\title{
Triplet Thermal Relaxation Study as a Probe of Weak Interdimers of Porphyrin Derivatives
}

\author{
D. Wróbel · A. Biadasz · B. Bursa
}

Received: 24 March 2011 / Accepted: 8 July 2011 / Published online: 4 August 2011

(C) The Author(s) 2011. This article is published with open access at Springerlink.com

\begin{abstract}
This article deals with results concerning the study of interacting dyes which are able to create weak interdimers. Two groups of organic systems: phthalocyanines (di-ethanol-amine and di-octane-amine) and pyridyl porphyrins (zinc, copper, and free-base) covalently linked to polyethylene glycol (PEG) in water and organic solvents (dioxane, dimethylsulfoxide) were investigated. Absorption, fluorescence, and photoacoustics were used as experimental methods but particular attention was paid to light-induced optoacoustic spectroscopy to follow the dye's triplet population and triplet thermal relaxation to study intermolecular interactions. It has been shown that even the weak interactions of the organic dyes under study is not detectable by absorption and only slightly by fluorescence is it possible to follow interactions by complementary photothermal methods. The results obtained for selected phthalocyanines and covalent porphyrin-polymer samples evidently show that the lightinduced optoacoustic experiment is a perfect tool in the detection of weakly interacting aggregates.
\end{abstract}

Keywords Fluorescence lifetime - Interdimer · Porphyrin derivatives · Time-resolved optoacoustics $\cdot$ Triplet thermal relaxation

\section{Introduction}

Molecular aggregates play very essential roles in many fields: in the physics of molecular crystals [1,2], in non-crystalline molecular systems with van der Waals and hydrogen interactions [3], in covalently bonded supermolecular units [4], in modeling of the

D. Wróbel $(\varangle) \cdot$ A. Biadasz · B. Bursa

Faculty of Technical Physics, Institute of Physics, Poznan University of Technology, Poznan, Poland e-mail: danuta.wrobel@put.poznan.pl 
structure of photosynthetic organisms and processes [5], in modern optoelectronics [6], and in the creation of organic semiconductors [7]. Aggregation of porphyrins has been shown to have marked effects on catalytic and photophysical properties [8].

One of the first demonstrations of the aggregated structure creation and their spectral properties was carried out by Kautsky et al. [9], Levison et al. [10], and Szent-Györgyi [11], and theoretical approaches of aggregate modeling were proposed by Förster in his quasi-classic vector model [12] and by Kasha et al. [2] in the exciton model.

Usually, in aggregates some changes in photophysical features can be easily demonstrated by absorption behavior; their modification depends on the type of aggregates and it results in the appearance of strong shifts (they can reach values up to about $2000 \mathrm{~cm}^{-1}$ ) or splitting of absorption bands [13]. Also, fluorescence quenching and changes in thermal deactivation could be associated with aggregate formation due to enhancement of the triplet state $[14,15]$. The aggregate structures differ one from another by the geometrical arrangement of their dipole moments. In the ideal H aggregate, the molecular frames are oriented face-to-face with parallel transition dipole moments of interacting monomer units and oriented perpendicularly to the line of the molecular centers. In the ideal J aggregate, the polarization axis of the electronic transition is directed along the line of the molecular centers. In a double molecule with the coplanar transition dipoles inclined to the interconnected axis, an angle between the dipole moment's directions ranges from $54.7^{\circ}$ to $90^{\circ}$ and $0^{\circ}$ to $54.7^{\circ}$ in $\mathrm{H}$ and $\mathrm{J}$, respectively [16-19]. The blue and red absorption shifts are expected to appear in the absorption spectrum of the $\mathrm{H}$ and $\mathbf{J}$ aggregates, respectively [2,20]. Marked changes can be also observed in their fluorescence behavior and consequently in nonradiative processes; thermal relaxation is expected to be changed in aggregated dyes [21]. The results of an exciton model study [2] show that triplet state population can be enhanced in aromatic aggregates due to interactions of the component molecules. Moreover, fluorescence could compete with thermal deactivation and it leads to a decrease of fluorescence and its lifetime.

However, when weak interactions between molecule species take place and even that no significant changes in absorption and only slightly in fluorescence are observed, it is possible to follow weakly interacting molecules by performing enhancement of the triplet population by the use of complementary spectroscopic methods such as photoacoustics (PAS) and light-induced optoacoustic spectroscopy (LIOAS) [22-24].

One of the most interesting systems for our studies is an organic dye composed of $\pi$-electron conjugated rings. Organic dyes have been interesting materials for decades in fields of novel science and technology [25-28]. The great development in novel photonics, photomedicine, laser techniques, compact discs, environmental protection, and artificial photosynthesis as well as other applications is also noticed and described in some papers (e.g., [29-34]).

Very attractive molecular materials such as photoconverters in photonics could be a family of synthetic phthalocyanines and porphyrins because of their electron donor-acceptor features, and they can find applications in devices where electron and energy transfer processes are essential [25-27,35-38]. However, some porphyrins and phthalocyanines tend to form aggregated species under specific conditions and their ability to create aggregates depends very strongly on their molecular structure and environment. Thus, it is important to consider the tendency of organic dyes to create 
molecular aggregates. Firstly, molecular aggregates could be disadvantageous because their presence can diminish dye photoactivity in photovoltaics [39]; secondly, organic dyes play an essential role in searching for new materials that can be used as organic semiconductors and in minimizing the size of electronic devices of low power [7].

The general aim of this article is to follow molecular interactions between phthalocyanine molecules and between porphyrins in systems with a polymer and to present the results of the systems in which weakly conjugated interdimers can be formed. In this article we study two groups of organic systems: non-fluorescent metal-free di-ethanol-amine and di-octane-amine phthalocyanines substituted with a long alkyl chain in dimethylsulfoxide (DMSO) as well as pyridyl porphyrins (zinc, copper, and free-base) covalently linked to polyethylene glycol (PEG) in water and organic solvents (dioxane and DMSO). The phthalocyanine samples dissolved in DMSO were studied in a wide range of dye concentrations to follow the activity of these dyes to aggregate formation. The porphyrin-PEG systems were studied in organic solvents of different polarities to follow the conditions for diminishing or even avoiding creation of aggregates.

This article is a mini-review of the studies and shows how one can take advantage of the LIOAS method accompanied with the photoacoustic method supported by other spectroscopic examinations such as absorption and fluorescence to follow weakly interacting dye molecules in interdimers for the case when absorption spectroscopy (and/or weak fluorescence) is not fully useful for this purpose [21-24]. Particular attention was paid on the LIOAS experiments to follow the dye's triplet population, triplet thermal relaxation, and intermolecular interactions occurring in the investigated systems. The fluorescence natural lifetimes and triplet thermal relaxation times were evaluated, and their values versus those found for monomeric species were analyzed to follow the creation of intermolecular dimers. We showed that the photothermal experiments (PAS and LIOAS) are particularly useful in studies of interactions between metal-free phthalocyanine dye molecules which do not fluoresce and porphyrins covalently linked to PEG.

\section{Materials and Experimental Methods}

Two phthalocyanine dyes: di-ethanol-amine phthalocyanine (designated here as 1) and di-octane-amine phthalocyanine (designated here as 2) were investigated. The dyes were prepared according to the procedure described in $[40,41]$. The dyes were dissolved in DMSO $\left(\varepsilon_{\text {DMSO }}=46.7\right)$ and their concentrations were: $10^{-5} \mathrm{M}, 10^{-4} \mathrm{M}$, and $10^{-3} \mathrm{M}$; spectroscopic measurements were performed in $1 \mathrm{~cm}, 1 \mathrm{~mm}$, or $60 \mu \mathrm{m}$ quartz cuvettes. The molecular structures of the phthalocyanine dyes are shown in Fig. 1a.

Three porphyrin dyes: zinc, copper, and free-base 5-(4-pyridyl)-10,15,20-tri(4methyloxyphenyl)porphyrins (named shortly as porphyrins) covalently linked to PEG of different molecular weights (35000 $(n=800), 20000(n=455), 8000$ $(n=182), 6600$ ( $n=150)$; $n$-numbers of mers) were also chosen for our investigations. The polymers and the samples were prepared as described in $[42,43]$. The molecular structures of the investigated samples (designated here as $\mathbf{3 , 4}$, and $\mathbf{5}$ ) are 

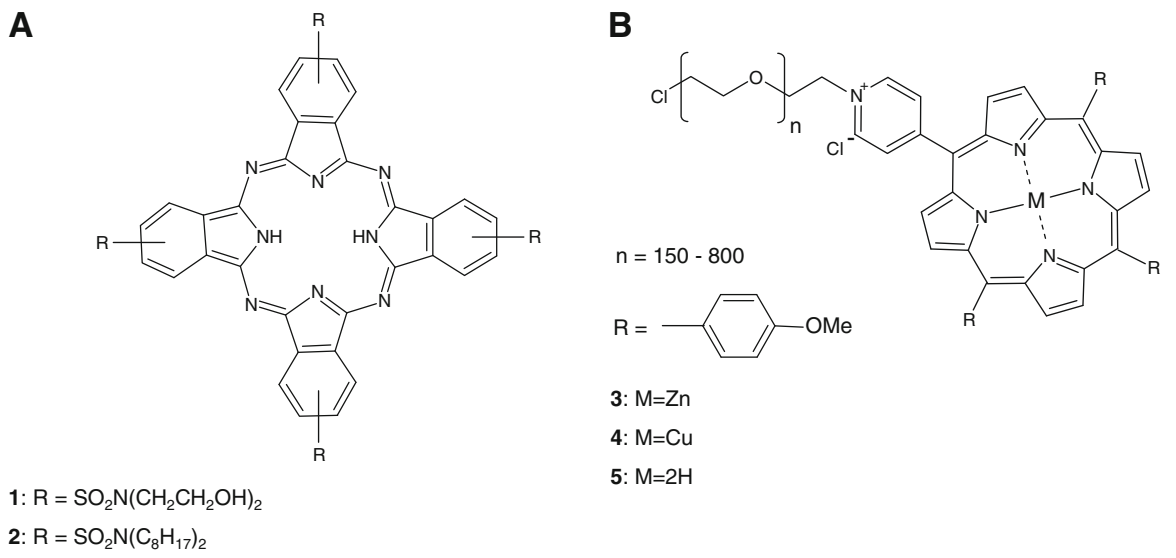

Fig. 1 Molecular structure of the investigated systems: (a) Di-ethanol-amine phthalocyanine (1), di-octaneamine phthalocyanine (2) and (b) porphyrin-PEG (3-5)

presented in Fig. 1b; ZnP-PEG35000 (3 $\left.3^{\mathrm{I}}\right)$, ZnP-PEG20000 (3 $\left.3^{\mathrm{II}}\right)$, ZnP-PEG6600 $\left(3^{\mathrm{III}}\right)$,

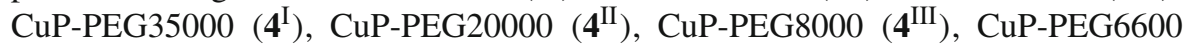
$\left(4^{\mathrm{IV}}\right), \mathrm{H}_{2} \mathrm{P}-\mathrm{PEG} 35000\left(\mathbf{5}^{\mathrm{I}}\right), \mathrm{H}_{2} \mathrm{P}-\mathrm{PEG} 20000\left(\mathbf{5}^{\mathrm{II}}\right), \mathrm{H}_{2} \mathrm{P}-\mathrm{PEG} 8000\left(\mathbf{5}^{\mathrm{III}}\right)$, and $\mathrm{H}_{2} \mathrm{P}-$ PEG6600 $\left(\mathbf{5}^{\mathrm{IV}}\right)$. The samples were dissolved in dioxane $\left(\varepsilon_{\text {dioxane }}=2.2\right)$, DMSO, and water $\left(\varepsilon_{\text {water }}=78.4\right)$. The dye species concentrations in the samples are in the range of $10^{-6} \mathrm{M}$ and $10^{-4} \mathrm{M}$ depending on the measurements.

Absorption spectra were monitored with a Carl-Zeiss spectrophotometer Specord M40 in the range of $350 \mathrm{~nm}$ to $800 \mathrm{~nm}$ (phthalocyanines) and $380 \mathrm{~nm}$ to $700 \mathrm{~nm}$ (porphyrin-polymer samples). Steady-state fluorescence was excited at $\lambda_{\mathrm{ex}}=609 \mathrm{~nm}(\mathbf{1}$ and 2) or at $421 \mathrm{~nm}<\lambda_{\mathrm{ex}}<431 \mathrm{~nm} \mathrm{(3,4}$, and 5-at the maximum of the proper Soret band) and collected in the range of $620 \mathrm{~nm}$ to $800 \mathrm{~nm}$ (phthalocyanines) and $575 \mathrm{~nm}$ to $800 \mathrm{~nm}$ (porphyrin-polymer samples). The relative fluorescence quantum yield $\left(\Phi_{\mathrm{F}}\right)$ and fluorescence natural lifetime $\left(\tau_{\mathrm{N}}\right)$ of the samples were evaluated on the basis of the absorption and fluorescence spectra according to the methods described elsewhere $[44,45]$

$$
\Phi_{\mathrm{F}}=\Phi_{\mathrm{R}} \frac{I}{I_{\mathrm{R}}} \frac{A_{\mathrm{R}}}{A} \frac{n^{2}}{n_{\mathrm{R}}^{2}}
$$

where $\Phi_{\mathrm{R}}$ is the fluorescence quantum yield of a reference sample (coumarine 510 in DMSO [44]), $I$ and $I_{\mathrm{R}}$ are the integrated fluorescences of the sample and reference, respectively, $A$ and $A_{\mathrm{R}}$ are the absorbances of the sample and reference, respectively, and $n$ and $n_{\mathrm{R}}$ are the refractive indices of the sample and reference, respectively. Corrections for re-absorption of fluorescence light and secondary fluorescence effects were taken into account, and the maximal error does not exceed $5 \%$. The natural lifetime can be expressed from [44]

$$
\frac{1}{\tau_{\mathrm{N}}}=2.88 \times 10^{-9} n^{2} \frac{\int\left(F(\lambda) / \lambda^{2}\right) \mathrm{d} \lambda}{\int F(\lambda) \times \lambda \mathrm{d} \lambda} \int \frac{\varepsilon(\lambda)}{\lambda} \mathrm{d} \lambda,
$$


where $n$ is the refractive index of the sample and the integrals of $F(\lambda)$ and $\varepsilon(\lambda)$ are the areas under the fluorescence and absorption spectra, respectively.

The photoacoustic measurements in the range of $300 \mathrm{~nm}$ to $800 \mathrm{~nm}$ were carried out with a one-beam MTEC photoacoustic spectrometer [46]. Light modulation frequencies of the light beam were $(8,10,15,20$, and 30) $\mathrm{Hz}$ at a constant phase shift. The sample was embedded in a photoacoustic chamber filled with helium gas, and the acoustic signal was detected with a very sensitive microphone. A blackbody was used for correction of the photoacoustic spectra for the device response.

The kinetics of photothermal processes and triplet population were measured with the use of LIOAS $[46,47]$. The samples were illuminated by a flash GL-3300/GL301 nitrogen laser (Photon Technology Int.), combined with a dye laser; $\lambda_{\mathrm{ex}}=415 \mathrm{~nm}$ (1 and $\mathbf{2})$ or $427 \mathrm{~nm}(\mathbf{3}, \mathbf{4}$, and $\mathbf{5})$ of a pulse duration of $0.2 \mathrm{~ns}$ to $0.8 \mathrm{~ns}$. The obtained waveform is a photothermal signal, and it contains information about fast and slow non-radiative relaxation of the samples. In our experiments the LIOAS waveform signals of the samples as well as of the reference dye (bromocresol purple-BCP; $\mathrm{RdH}$ Laborchemikalien) were measured. The LIOAS measurements were carried out at $20{ }^{\circ} \mathrm{C}$ in a nitrogen atmosphere. The photothermal data were analyzed using two methods: Marti et al. and Rudzki et al. which are widely described in the literature [48,49]. Marti's approach [48] gives information on a part of the energy changed into heat promptly (expressed by $\alpha$ parameter) in the time range from $0 \mu \mathrm{s}$ to $0.4 \mu \mathrm{s}$ (resolution of the LIOAS device) with the use of

$$
H=k \alpha E_{\mathrm{L}}\left(1-10^{-A}\right)
$$

where $H$ is the maximal intensity of the LIOAS waveform, $k$ is a geometrical and electrical set-up factor of the device, $A$ is the absorbance of the sample, and $E_{\mathrm{L}}$ is the laser energy. LIOAS data deconvolution (Rudzki et al. [49] approach) can be done with

$$
y=R(t) \sum K_{i} \exp \left(-t / \tau_{i}\right)
$$

(where $R(\mathrm{t})$ is the weight factor of deconvolution, $K_{i}$ is a pre-exponential factor, and $\tau_{i}$ is the lifetime of the $i$ th transient). Equation 4 is used to determine the following parameters: $K_{1}$ (part of the energy changed promptly into heat in time duration from $0 \mu \mathrm{s}$ to $0.4 \mu \mathrm{s}$; it is equivalent to $\alpha$ parameter in Eq. 3), $K_{2}$ (a part of the energy changed into heat in slow processes in the time range of $0.4 \mu \mathrm{s}$ to $5 \mu \mathrm{s}$ ), and $\tau_{2}$ (thermal relaxation time). In this experiment, BCP was taken as a reference sample under the supposition that the whole energy absorbed by this molecule is changed into heat in prompt processes in a time shorter than $0.4 \mu \mathrm{s}(\alpha=1)$ [49].

The triplet population was evaluated on the basis of [48]

$$
\Phi_{\mathrm{T}}=\frac{(1-\alpha) E_{h v}}{E_{\mathrm{T}}}-\frac{\Phi_{\mathrm{F}} E_{\mathrm{F}}}{E_{\mathrm{T}}},
$$


where $\alpha$ is a part of the energy changed promptly into heat, $\Phi_{\mathrm{F}}$ is the fluorescence quantum yield, $E_{\mathrm{F}}$ and $E_{\mathrm{T}}$ are the energies of fluorescence and the triplet state with respect to the ground state, respectively, and $E_{h v}$ is the energy of the laser beam.

\section{Results and Discussion}

In this article we present the results of the study done for two different systems: two metal-free non-substituted phthalocyanine dyes [21] and covalent porphyrin-polymer systems $[23,24]$. We divided our presentation into two parts; in the first we show the absorption and fluorescence results of our systems - the phthalocyanine dyes and the porphyrin-polymer samples were examined in the wide range of concentrations in solvents of different polarities (dioxane, water, and DMSO), in the second part of our investigations we concentrate on the PAS and LIOAS examinations to show how one can take advantage from the PAS and LIOAS methods to follow the presence of weakly interacting aggregates.

\subsection{Electronic Absorption and Fluorescence Investigations}

Phthalocyanine dyes are the first group of the samples under our studies. The electronic absorption spectra of $(\mathbf{1}, \mathbf{2})$ are shown in Fig. $2 \mathrm{a}$ and $\mathrm{b}$ (dye concentrations range from $10^{-5} \mathrm{M}$ to $10^{-3} \mathrm{M}$ ). The Soret and Q bands (Table 1) are located at about $350 \mathrm{~nm}$ and $672 / 676 \mathrm{~nm}$, respectively, as expected for phthalocyanine dyes in an organic solvent $[25,37,50]$. The presented absorption spectra show some changes in the shapes with increasing concentration-some broadening and increasing band and a small band's shift are seen in the Q band. No spectacular changes are observed in the Soret band and the $\mathrm{Q}$ in the range 672/676 nm (only a slight band shift is observed in sample 2); however, new humps are seen on the "red" part of the spectra. The increasing intensity is also observed in the absorption range of $606 / 607 \mathrm{~nm}$. All these changes in the absorption (even the small ones) would suggest creation of some aggregates of dyes $\mathbf{1}$ and $\mathbf{2}[16,17,19,51]$. The appearance of the bands at $703 \mathrm{~nm}$ could rather be assigned to the vibrational mode of the alkyl chains covalently linked to the indole units which vanish when aggregates are created (in the highly concentrated samples); in the metalfree non-substituted phthalocyanines, this band is not observed [25]. The presence of the weakly interacting interdimers (or higher associates) is also supported by observed diminishing of the extra bands at about $703 \mathrm{~nm}$ with increasing concentration; when the dye concentrations increase, the vibrational modes could be quenched as a result of the presence of aggregates and changes in conformation of the associates. The fluorescence of $\mathbf{1}$ and $\mathbf{2}$ is extremely weak (not shown), and their fluorescence quantum yields (evaluated versus rodamine 6G) are less than 0.001 (i.e., in the range of the experimental accuracy). There could be two reasons for poor emission of the dyes: the presence of aggregates and/or substitution with the long chains [50]. Since the dyes fluoresce only slightly, the fluorescence examinations are not useful in the study of weak aggregates. The main absorption and fluorescence parameters are reported in Table 1. 

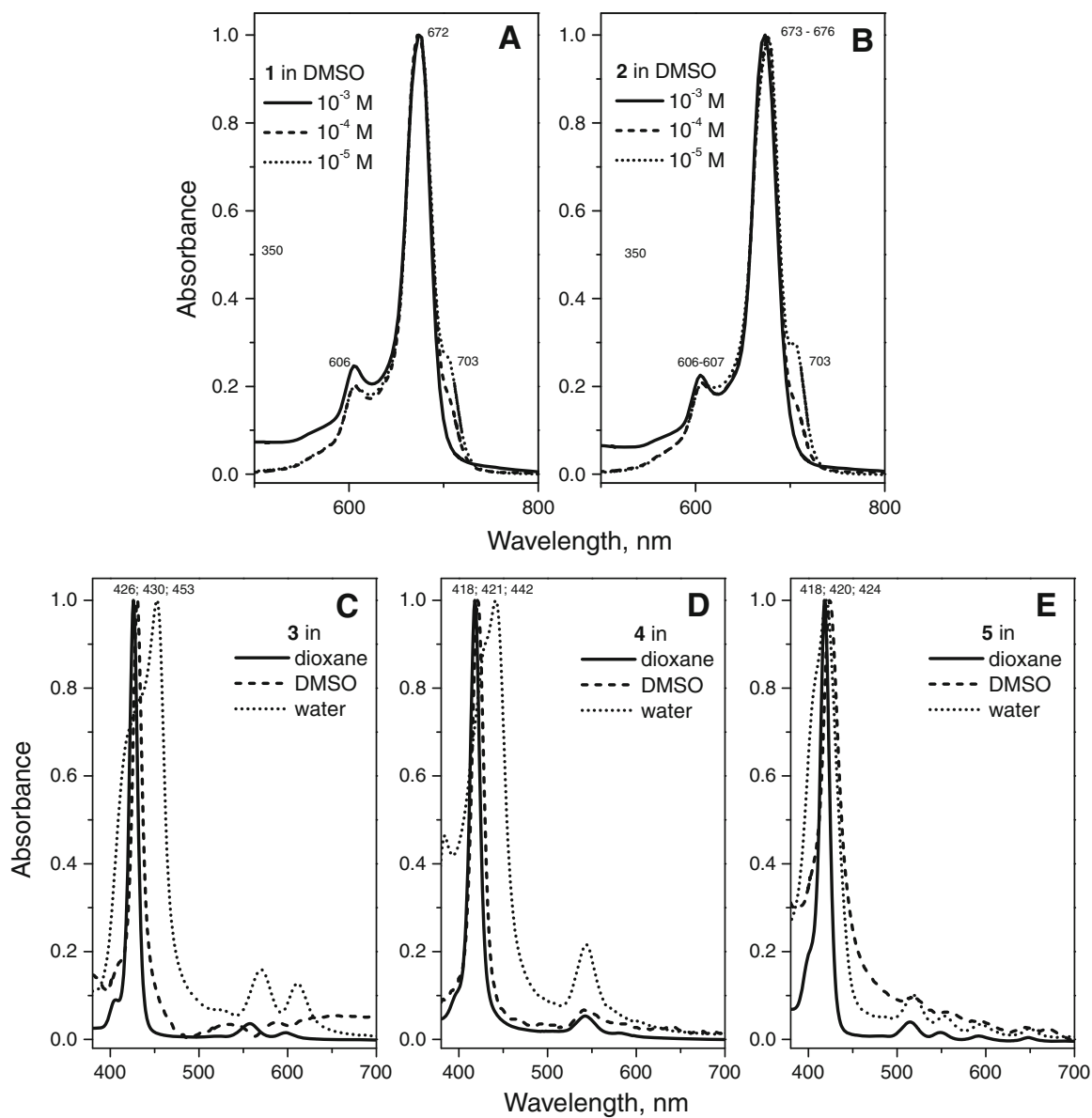

Fig. 2 Exemplary absorption spectra (normalized to unity at the maximal band): (a) $\mathbf{1}$ in DMSO, (b) 2 in DMSO, (c)-(e): 3-5 in dioxane, DMSO, and water; $c=10^{-6} \mathrm{M}$ in dioxane and water, $c=10^{-5} \mathrm{M}$ in DMSO; based on [21,23,24]

Apart from the small blue absorption band shifts in the Q region, the increase of the $606 / 607 \mathrm{~nm}$ bands and small broadening of the bands are observed. The half-width of the absorption band evaluated for the phthalocyanine monomers of $\mathbf{1}$ and $\mathbf{2}$ are about $3.0 \times 10^{5} \mathrm{~cm}^{-1}$ (the Soret band) and $1.2 \times 10^{5} \mathrm{~cm}^{-1}$ (the Q band), respectively. Under high concentration conditions, they are $3.2 \times 10^{5} \mathrm{~cm}^{-1}$ to $3.4 \times 10^{5} \mathrm{~cm}^{-1}$ (1) and $1.7 \times 10^{5} \mathrm{~cm}^{-1}(2)$, respectively, and they could indicate the presence of a tiny amount of dye aggregates. Since the absorption bands are slightly blue shifted, we can suppose the creation of a type of the H-aggregates. DMSO is a polar solvent which can protect dyes against aggregation due to strong interactions between the dye and solvent molecules [44]. However, in some cases interactions between dye molecules could exceed interactions between a dye molecule and solvent. Thus, it is rather difficult to judge as to the presence or absence of some aggregates particularly when weak interactions are modestly detectable by absorption and/or weakly by fluorescence even 
Table 1 Selected absorption and fluorescence parameters of the investigated molecular systems in organic solutions (in $\mathrm{DMSO}^{(\mathrm{DMSO})}$, water $^{(\mathrm{w})}$, or dioxane ${ }^{(\mathrm{d})}$ )

\begin{tabular}{|c|c|c|c|c|c|c|c|c|c|}
\hline Sample & $c(\mathrm{M})$ & $\begin{array}{l}\lambda_{\mathrm{S}} \\
(\mathrm{nm})\end{array}$ & $\begin{array}{l}\lambda_{\mathrm{Q}} \\
(\mathrm{nm})\end{array}$ & $\begin{array}{l}\mathrm{S} \Delta v_{1 / 2} \\
\left(\mathrm{~cm}^{-1}\right)\end{array}$ & $\begin{array}{l}\mathrm{Q} \Delta v_{1 / 2} \\
\left(\mathrm{~cm}^{-1}\right)\end{array}$ & $\begin{array}{l}\lambda_{\mathrm{F}} \\
(\mathrm{nm})\end{array}$ & $F R$ & $\Phi_{\mathrm{F}}$ & $\begin{array}{l}\tau_{\mathrm{N}} \\
(\mathrm{ns})\end{array}$ \\
\hline \multirow[t]{2}{*}{$\mathbf{1}^{\text {(DMSO) }}$} & $10^{-5}$ & 350 & 606.672 & $3.1 \times 10^{5}$ & $1.2 \times 10^{5}$ & 682 & - & - & - \\
\hline & $10^{-3}$ & 348 & 606.672 & $3.4 \times 10^{5}$ & $1.7 \times 10^{5}$ & & & & \\
\hline \multirow[t]{2}{*}{$\mathbf{2}^{\text {(DMSO) }}$} & $10^{-5}$ & 350 & 607.676 & $3.0 \times 10^{5}$ & $1.2 \times 10^{5}$ & 682 & - & - & - \\
\hline & $10^{-3}$ & 350 & 606.673 & $3.2 \times 10^{5}$ & $1.7 \times 10^{5}$ & & & & \\
\hline $\mathbf{3}^{\mathrm{I}(\mathrm{DMSO})}$ & $10^{-5}$ & 430 & 565.600 & $0.6 \times 10^{3}$ & & 610.660 & 1.77 & 0.06 & 8.7 \\
\hline $\mathbf{3}^{\mathrm{II}(\mathrm{DMSO})}$ & $10^{-5}$ & 430 & - & $0.5 \times 10^{3}$ & & 610.660 & 2.12 & 0.10 & 8.1 \\
\hline $\mathbf{3}^{\mathrm{III}(\mathrm{w})}$ & $\sim 10^{-6}$ & 453 & 569.610 & $2.6 \times 10^{3}$ & & 619.669 & 1.66 & $\sim 0.005$ & 1.4 \\
\hline $3^{\mathrm{III}(\mathrm{d})}$ & $\sim 10^{-6}$ & 426 & 558.598 & $0.6 \times 10^{3}$ & & 606.655 & 1.82 & 0.03 & 3.9 \\
\hline $\mathbf{4}^{\mathrm{I}(\mathrm{DMSO})}$ & $10^{-5}$ & 421 & - & $0.8 \times 10^{3}$ & & & & & \\
\hline $4^{\mathrm{II}(\mathrm{DMSO})}$ & $10^{-5}$ & 421 & - & $0.9 \times 10^{3}$ & & & & & \\
\hline $4^{\mathrm{III}(\mathrm{DMSO})}$ & $10^{-5}$ & 421 & - & $0.9 \times 10^{3}$ & - & - & - & - & - \\
\hline $4^{\mathrm{IV}(\mathrm{w})}$ & $\sim 10^{-6}$ & 442 & 544 & $2.3 \times 10^{3}$ & & & & & \\
\hline $4^{\mathrm{IV}(\mathrm{d})}$ & $\sim 10^{-6}$ & 418 & 543 & $0.7 \times 10^{3}$ & & & & & \\
\hline $\mathbf{5}^{\mathrm{I}(\mathrm{DMSO})}$ & $10^{-5}$ & 424 & $520.560,595.650$ & $1.0 \times 10^{3}$ & & 653.715 & 3.32 & 0.08 & 24.3 \\
\hline $5^{\mathrm{II}(\mathrm{DMSO})}$ & $10^{-5}$ & 422 & - & $0.8 \times 10^{3}$ & & 652.715 & 4.10 & 0.16 & 9.8 \\
\hline $5^{\mathrm{III}(\mathrm{DMSO})}$ & $10^{-5}$ & 421 & - & $0.7 \times 10^{3}$ & - & 653.716 & 4.15 & 0.11 & 15.1 \\
\hline $\mathbf{5}^{\mathrm{IV}(\mathrm{w})}$ & $\sim 10^{-6}$ & 420 & $518.553,597.649$ & $2.0 \times 10^{3}$ & & 656.711 & 1.31 & 0.03 & 2.0 \\
\hline $\mathbf{5}^{\mathrm{IV}(\mathrm{d})}$ & $\sim 10^{-6}$ & 418 & $514.549,593.649$ & $0.1 \times 10^{3}$ & & 654.719 & 4.07 & 0.09 & 4.2 \\
\hline
\end{tabular}

$c$ Concentration, $\lambda$ absorption wavelength at the maximal intensity, $\Delta v_{1 / 2}$ spectral width of the absorption band, $\lambda_{\mathrm{F}}$ fluorescence wavelength, $F R$ fluorescence band intensity ratio, $\Phi_{\mathrm{F}}$ fluorescence quantum yield, $\tau_{\mathrm{N}}$ natural lifetime, $S$ Soret band, $Q$ long wavelength band. Based on [21,23,24]

$\Delta \lambda= \pm 1 \mathrm{~nm}, \Delta\left(\Delta v_{1 / 2}\right)= \pm 0.1 \times 10^{5}(\mathbf{1}, \mathbf{2})$ or $\pm 0.1 \times 10^{3}(\mathbf{3}, \mathbf{5}), \Delta \Phi_{\mathrm{F}}= \pm 0.01, \Delta \tau_{\mathrm{N}}= \pm 0.03 \mathrm{~ns}$

though the fluorescence experiment is more selective and sensitive in monitoring of weak interacting molecules than the absorption one. Therefore, we also use the PAS and LIOAS examinations as complementary methods to absorption and fluorescence (Sect. 3.2).

In the second stage of our studies, we focus our attention on the porphyrin-polymer systems; the samples in dioxane $\left(3^{\mathrm{III}}, \mathbf{4}^{\mathrm{IV}}, \mathbf{5}^{\mathrm{IV}}\right)$ are the standard samples for our further investigations in water and DMSO (selected absorption data are also gathered in Table 1). Exemplary absorption spectra of 3, 4, and $\mathbf{5}$ in dioxane, water, and DMSO are shown in Fig. 2c-e. As observed, the porphyrin dye moieties absorb intensively in the range from $418 \mathrm{~nm}$ to $453 \mathrm{~nm}$ (Soret bands) and only modestly in the Q region from about $500 \mathrm{~nm}$ to about $700 \mathrm{~nm}$; in metallic porphyrins $\mathbf{3}$ and 4, two Q bands are characteristic for monomeric porphyrins (due to the $\mathrm{D}_{4 \mathrm{~h}} \pi$-electron symmetry), and in the absorption spectra of the porphyrin of the $D_{2 \mathrm{~h}}$ symmetry, four Q bands are seen in 5 [26]. In the investigated porphyrin-PEG samples, no spectacular influence of the polymer chains is observed [23]. Thus, we will not discuss this problem, but rather we focus our study mostly on the influence of the solvent polarity on interactions between the dye molecules. The absorption band's locations and the values of the half-widths 
of the maxima of the samples in dioxane (solvent of low polarity) are as observed for porphyrin monomeric species in other organic solvents [52-56].

Occurrence of the monomeric porphyrin species in samples $\mathbf{3}, \mathbf{4}$, and $\mathbf{5}$ in dioxane was evidently shown; the Soret bands are very narrow and their half-widths $\left(\Delta v_{1 / 2}\right)$ range from $0.1 \times 10^{3} \mathrm{~cm}^{-1}$ to $0.7 \times 10^{3} \mathrm{~cm}^{-1}$ depending on the metal ion (or its lack) complexed with the porphyrin subunits [23]. The absorption band's positions in the Soret and Q regions in water are changed as seen in Fig. 2c-e. The Soret band half-widths of samples $\mathbf{3}, \mathbf{4}$, and $\mathbf{5}$ in water ranged from about $2.0 \times 10^{3} \mathrm{~cm}^{-1}$ up to $2.6 \times 10^{3} \mathrm{~cm}^{-1}$. Thus, when the absorption spectra of the samples in water are compared to those in dioxane, the spectacular differences in their spectral characters are observed; not only shifts and broadening of the bands are observed but also new humps are well recognized. These results can be interpreted as due to the existence of some aggregated porphyrin moieties when the samples are dissolved in water $[2,26,27]$. On the one hand, the absorption results of the samples in water differ from those in DMSO. For example, the values of the band half-widths in DMSO are much smaller than those in water and only slightly larger when compared to those in dioxane (see Table 1).

Creation of some aggregated species could be confirmed by emission examinations, which compare the fluorescence results of $\mathbf{3}$ to those of $\mathbf{5}$ in dioxane, DMSO, and water (Fig. 3); (sample 4 does not fluoresce [21]). These results clearly show that the solvent has a marked influence on the fluorescence behavior of the samples; in dioxane the emission spectra are characteristic for monomeric porphyrins [26,27,42,45], whereas in water the fluorescence spectrum shapes and band positions are strongly changed on the wavelength scale. The changes in fluorescence parameters: the fluorescence quantum yields ( $\Phi_{\mathrm{F}}$ - evaluated with respect to coumarine) and the natural lifetimes $\left(\tau_{\mathrm{N}}\right)$ are also observed. The $\Phi_{\mathrm{F}}$ values of samples $\mathbf{3}$ and $\mathbf{5}$ in water are $\sim 0.005$ and 0.03 , respectively, and they are higher in dioxane (up 0.09) [26,52]. Shortening of $\tau_{\mathrm{N}}$ is also noticed ( the values of the natural life time of the investigated porphyrin samples versus $\tau_{\mathrm{N}}$ of zinc tetraphenylporphyrin) in DMSO $(25 \mathrm{~ns})[53,56]$. There could be at least three reasons for the observed changes in the fluorescence parameters: solvent polarity effect and aggregate formation as well as the presence of PEG [23]. The solvent polarity effect and aggregate formation are closely connected to each other. It is well known that it is difficult to avoid aggregate creation in water and the presence of aggregate species seems to be the main reason for our observations [23,25-27,56]

Markedly different absorption and fluorescence spectra of the same porphyrinPEG samples are found when the systems are dissolved in polar DMSO. Figure 2c-e shows exemplary absorption spectra of the samples $\left(\mathbf{3}^{\mathrm{I}}, \mathbf{4}^{\mathrm{I}}\right.$, and $\left.\mathbf{5}^{\mathrm{I}}\right)$ in DMSO (Table 1). Analysis of the absorption parameters of samples $\mathbf{3}^{\mathrm{I}}, \mathbf{3}^{\mathrm{II}}, \mathbf{4}^{\mathrm{I}}-\mathbf{4}^{\mathrm{III}}$, and $\mathbf{5}^{\mathrm{I}}-\mathbf{5}^{\mathrm{III}}$ in DMSO and those of their counterparts $3^{\mathrm{III}}, \mathbf{4}^{\mathrm{IV}}$, and $\mathbf{5}^{\mathrm{IV}}$ in water evidently imply some dissimilarity of the absorption parameters. The changes are also observed in the values of the half-width parameters; the band half-widths of the porphyrin subunits in the samples in DMSO are decreased when compared to those of the samples in water, and they are similar to those of the samples in dioxane (in dioxane monomeric structures are assumed to be present). However, even though no significant changes are observed in the electronic absorption spectra, we cannot exclude the appearance of weakly coupled porphyrin aggregates. The creation of some aggregated structures 


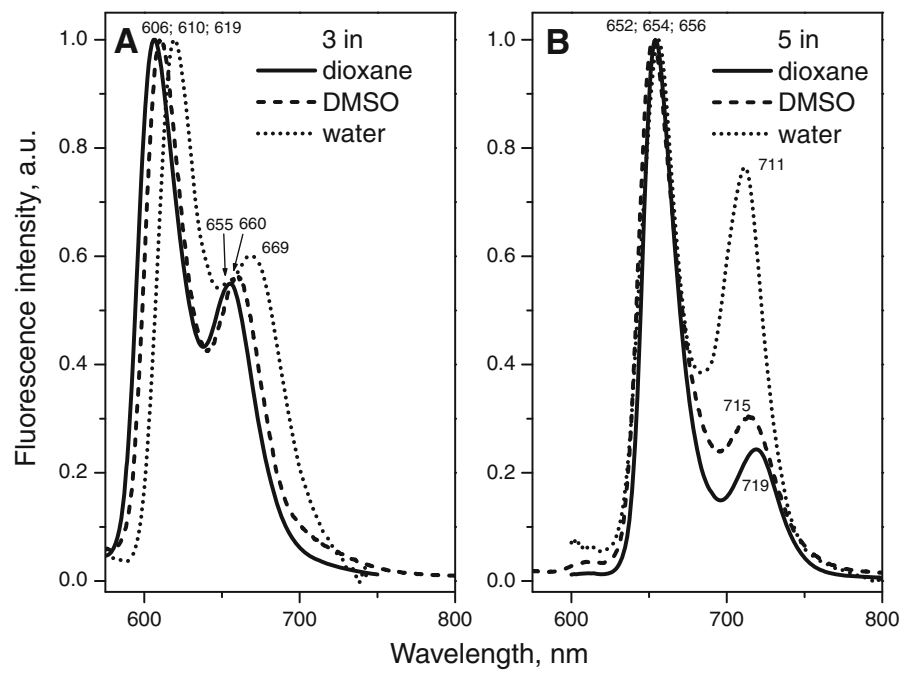

Fig. 3 Fluorescence spectra of the porphyrin-PEG samples in dioxane, DMSO or water (normalized to unity at the maximal band): (a) 3, (b) $\mathbf{5}, \lambda_{\text {ex }}$ : $421 \mathrm{~nm}<\lambda_{\mathrm{ex}}<431 \mathrm{~nm}$, and $c$ as in Fig. 2; based on $[21,23,24]$

is strongly influenced by the dye molecular structure, mainly by the presence of a metal ion, peripheral groups and also by the dye molecular symmetry. In the freebase porphyrin the symmetry is changed upon the presence of a metal ion $\left(D_{2 h}\right.$ vs. $\mathrm{D}_{4 \mathrm{~h}}$ ) and lead to an asymmetry. In our samples an extra asymmetry is introduced by the N-phenyl group linked directly to the polymer. A steric effect could protect dye molecules against aggregation as manifested in some porphyrins and phthalocyanines [57,58]. Moreover, DMSO can also protect molecules against aggregation [59].

Fluorescence of the porphyrin-polymer samples was excited at the wavelength matching the proper Soret band maxima. Figure $3 \mathrm{a}$ and $\mathrm{b}$ is an example of the fluorescence spectra of $\mathbf{3}$ and $\mathbf{5}$ in water, dioxane, and DMSO. The fluorescence features are sensitive to the metal ion within the porphyrin core or its lack [25-27,60] and to the molecular weights of the polymers [24]. Moreover, variations in the fluorescence behavior of our systems could be explained by coordination bonding to a metal ( $\mathrm{Zn}$, $\mathrm{Cu}$ ) and to the presence of oxygen in PEG. Analysis of the fluorescence spectra of samples $\mathbf{3}$ and $\mathbf{5}$ evidently confirms rather weak radiative deactivation of the singlet excited state of the zinc and free-base porphyrin moieties linked to PEG in DMSO ( $\Phi_{\mathrm{F}}$ ranges from 0.06 to 0.16 ). The $\Phi_{\mathrm{F}}$ values are similar to those of the monomeric porphyrin moieties in dioxane (0.03 and 0.09) [24,55], whereas for the samples in water, the quantum yields are declined and they are less than $0.01[24,55]$. Since the fluorescence quantum yields of the emitting species are not very much influenced by the presence of the polymer and its molecular weight, we can rather suggest its modest influence. Thus, the changes of the fluorescence spectra in DMSO with respect to those in water on the one hand and the similarity of fluorescence parameters to those in dioxane on the other hand led us to conclude about the presence of weakly interacting interdimers in our samples. 
Two fluorescence bands of the samples in DMSO are observed at $610 \mathrm{~nm}$ and 660 $\mathrm{nm}(3)$ and $652 / 653 \mathrm{~nm}$ and $715 / 716 \mathrm{~nm}$ (5). For the samples in dioxane and water, they are shifted as indicated in Table 1 . The changes of the band positions of the samples in DMSO with respect to those in the remaining solvents [23] can be assigned to differences in electrical susceptibilities of DMSO and dioxane and in universal interactions between the dye and solvent. Moreover, the values of the fluorescence band intensity ratios ( $F R$ in Table 1$)$ of the samples in DMSO $\left(F R=1.77-\mathbf{3}^{\mathrm{I}}, 2.12-\mathbf{3}^{\mathrm{II}}, 3.31-\mathbf{5}^{\mathrm{I}}\right.$, $4.10-\mathbf{5}^{\mathrm{II}}$, and $\left.4.15-\mathbf{5}^{\mathrm{III}}\right)$, versus those of the samples in water $\left(F R=1.66-3^{\mathrm{III}}\right.$, $\left.1.66-\mathbf{5}^{\mathrm{IV}}\right)$ and in dioxane $\left(F R=1.82-\mathbf{3}^{\mathrm{III}}, 4.07-\mathbf{5}^{\mathrm{IV}}\right)$ evidently confirm the presence of some weakly interacting dimers in DMSO. The shortening values of the evaluated fluorescence natural lifetimes $\left(\tau_{\mathrm{N}}\right)$ of the samples in DMSO (8.1 ns and 8.7 ns of $\mathbf{3}^{\mathrm{I}}, \mathbf{3}^{\mathrm{II}}, 9.8 \mathrm{~ns}$ to $24.3 \mathrm{~ns}$ of $\mathbf{5}^{\mathrm{I}}-\mathbf{5}^{\mathrm{III}}$ ) relative to those of the samples $\mathbf{3}^{\mathrm{III}}$ and $\mathbf{5}^{\mathrm{IV}}$ in water (about $1 \mathrm{~ns}$ to $2 \mathrm{~ns}$ ) and in dioxane (about $4 \mathrm{~ns}$ ) with respect to the lifetime of $25 \mathrm{~ns}$ of zinc tetraphenylporphyrin in DMSO without any substituents $[53,56]$ could be assigned to overlapping contributions of intramolecular charge transfer and interactions in molecular aggregates, e.g., processes that could lead to modification of the singlet-triplet transition in chromophores.

Since the absorption and fluorescence examinations do not give the univocal arguments as to the existence (or not) of aggregated structures in the samples in DMSO, we have carried out the PAS and LIOAS experiments to follow the generation of triplet states of the dye moieties.

\subsection{PAS and LIOAS Experiments}

In an aggregate that does not fluoresce or its fluorescence is rather weak [21], enhancement of its lowest triplet state can occur and thus deactivation processes could be modified. So, in our further discussion we take into consideration other processes, which could result in deactivation of the dye excited states. Photoacoustic studies provide information on non-radiative processes occurring in a dye with participation of the internal conversion and intersystem crossing transitions resulting in heat liberation contributed by the singlet and triplet states [61]. The LIOAS waveform is a photothermal signal and its kinetic analysis can distinguish prompt thermal processes from those which occur in microseconds [25].

First, we concentrate on the results obtained with PAS for the phthalocyanine dyes. Figure 4a shows an exemplary PAS result of 1 (at $v=8 \mathrm{~Hz}$ ). Phthalocyanines 1 and 2 convert partly excited energy into heat. The thermal deactivation parameters (TD) are evaluated as a ratio of the photoacoustic signal to the absorbance [61] and are reported in Table 2. The different values of $T D$ of 2 (1.1 and 0.6$)$ confirm the presence of aggregation effects in the concentrated samples. According to Rosencwaig theory [61], the PAS signal is expected to increase linearly with $1 / \sqrt{ } v$ ( $v$ is the light modulation frequency) provided that one spectral species is involved in thermal processes. However, it is not the case for samples $\mathbf{1}$ and $\mathbf{2}$. The values of the evaluated correlation factors (lower than 1) between expected theoretical [61] and experimental data indicate that not only one species contributes to non-radiative thermal processes and that the triplet states are involved in thermal relaxation of the low and highly concentrated 


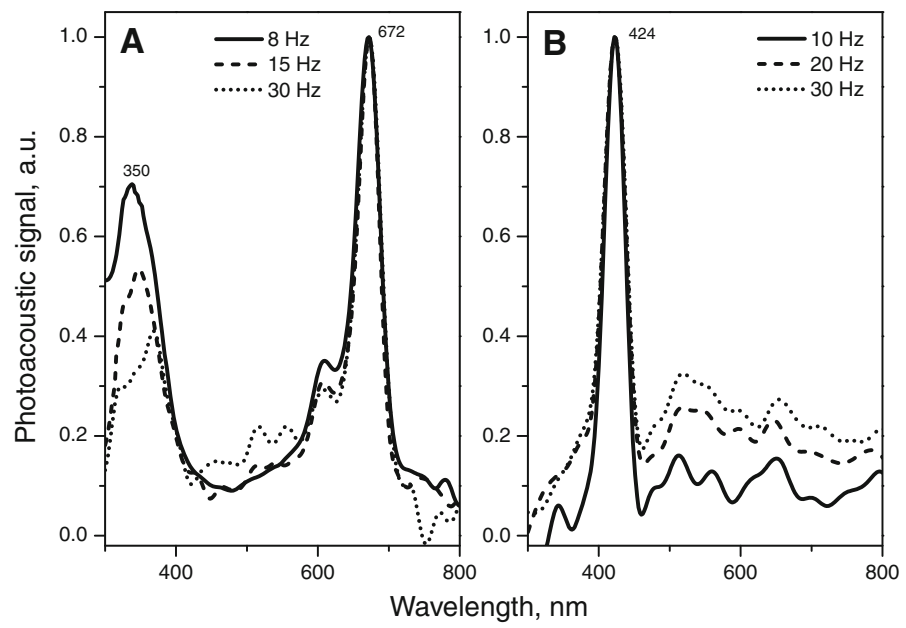

Fig. 4 Exemplary photoacoustic spectra (normalized to unity at the maximal band): (a) 1 in DMSO ( $v=8$ $\mathrm{Hz})$ and $(\mathrm{b}) \mathbf{5}^{\mathrm{I}}$ in DMSO $(v=10 \mathrm{~Hz})$; based on $[21,24]$

dye samples. Therefore, prompt and slow processes and the coexistence of monomeric and dimeric moieties of different relaxation decays should be considered. Since the PAS experiment gives information on global thermal processes occurring in samples without recognition of the prompt ones (with the participation of the singlet states) and those with a triplet state contribution, we have carried out the LIOAS study to follow the singlet-triplet transitions and triplet thermal relaxation. The results of $\mathbf{1}$ are presented in Fig. 5. The evaluated thermal parameters are compiled in Table 2. The $\alpha$ and $K_{i}$ values (evaluated from Eqs. (3) and (4)) are similar as expected [48,49] and give insight into the fast non-radiative processes occurring in a time range shorter than $0.4 \mu \mathrm{s}$ (in the resolution time range of our LIOAS device). As seen, more than $50 \%$ of the absorbed energy in samples $\mathbf{1}$ and $\mathbf{2}$ is converted promptly into heat. The sum of $K_{1}$ and $K_{2}$ is less than 1 ; it indicates the occurrence of other processes with triplet state participation (it is discussed widely in [21,62-64]). A spin-orbit perturbation enhancement could be neglected since we have used metal-free dyes in our experiment. The lack of fluorescence of samples $\mathbf{1}$ and $\mathbf{2}$ indicates the presence of very effective non-radiative channels of deactivation. The estimated values of triplet population $\left(\Phi_{\mathrm{T}}\right.$ in Table 2 ) show some tendency of intersystem crossing increasing in the concentrated samples $\left(10^{-3} \mathrm{M}\right.$ vs. $\left.10^{-5} \mathrm{M}\right)$. The enhancement of the triplet population could be expressed as the phosphorescence to fluorescence yield's ratio [2] and can occur when some aggregates are formed.

In our further discussion we take also into consideration the values of the decay time $\left(\tau_{2}\right)$. The decay times $\tau_{2}$ depend on both a kind of dye and its spectral form; their values range from $1.18 \mu \mathrm{s}$ to $1.28 \mu \mathrm{s}$ (monomeric dyes; $c=10^{-5} \mathrm{M}$ ) and $0.35 \mu \mathrm{s}$ to $0.98 \mu \mathrm{s}$ (the samples with monomer minorities and aggregates; $c=10^{-3} \mathrm{M}$ ) (Table 2). The decay time changes for the concentrated samples are additional confirmation of the occurrence of some aggregates. Thus, we can assign the lower values of $\tau_{2}$ of the concentrated samples to the dye aggregated structures which are present in the 


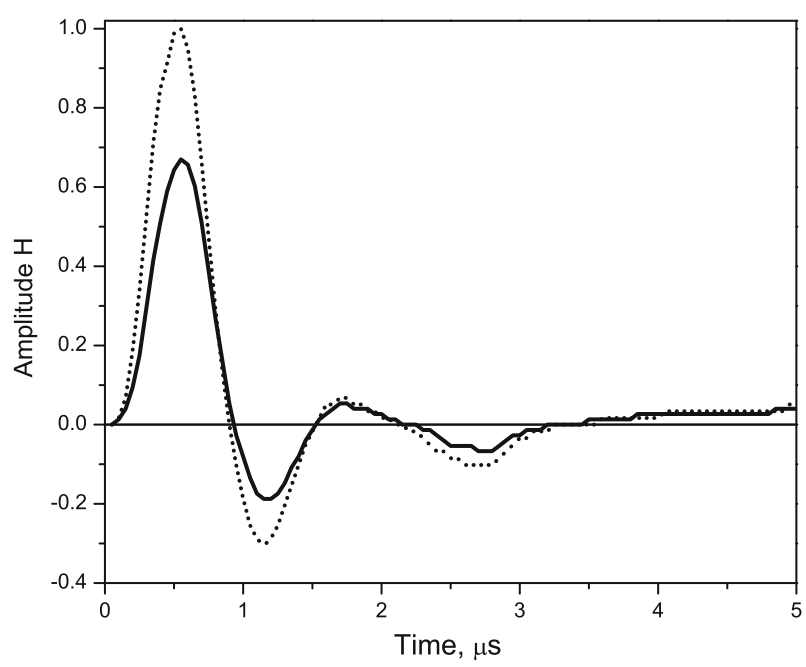

Fig. 5 Exemplary LIOAS waveform signals of 1 in DMSO; BCP—standard sample; based on [23]

Table 2 Photothermal parameters of the investigated molecular systems in organic solutions in DMSO.

\begin{tabular}{lllllllll}
\hline Sample & $c(\mathrm{M})$ & $T D$ & $\alpha$ & $K_{1}$ & $K_{2}$ & $\sum\left(K_{1}+K_{2}\right)$ & $\Phi_{\mathrm{T}}$ & $\tau_{2}(\mu \mathrm{s})$ \\
\hline $\mathbf{1}$ & $10^{-5}$ & - & 0.71 & 0.75 & 0.09 & 0.84 & 0.76 & 1.28 \\
& $10^{-4}$ & 1.0 & - & - & - & - & - & - \\
& $10^{-3}$ & 0.9 & 0.67 & 0.66 & 0.01 & 0.67 & 0.86 & 0.98 \\
$\mathbf{2}$ & $10^{-5}$ & - & 0.68 & 0.71 & 0.09 & 0.80 & 0.84 & 1.18 \\
& $10^{-4}$ & 0.6 & - & - & - & - & - & - \\
& $10^{-3}$ & 1.1 & 0.66 & 0.68 & 0.02 & 0.70 & 0.89 & 0.35 \\
$\mathbf{3}^{\text {I }}$ & $10^{-5}$ & 1.0 & 0.39 & 0.38 & 0.03 & 0.41 & - & 0.7 \\
$\mathbf{3}^{\text {II }}$ & $10^{-5}$ & 3.3 & 0.30 & 0.29 & 0.02 & 0.31 & - & 0.5 \\
$\mathbf{4}^{\text {I }}$ & $10^{-5}$ & 1.4 & 0.39 & 0.37 & 0.09 & 0.46 & - & - \\
$\mathbf{4}^{\text {II }}$ & $10^{-5}$ & 1.1 & 0.35 & 0.37 & 0.14 & 0.51 & - & - \\
$\mathbf{4}^{\text {III }}$ & $10^{-5}$ & 2.9 & 0.34 & 0.37 & 0.04 & 0.41 & - & 0.7 \\
$\mathbf{5}^{\text {I }}$ & $10^{-5}$ & 0.4 & 0.43 & 0.44 & 0.04 & 0.48 & - & 1.4 \\
$\mathbf{5}^{\text {II }}$ & $10^{-5}$ & 2.7 & 0.39 & 0.41 & 0.28 & 0.69 & - & 2.0 \\
$\mathbf{5}^{\text {III }}$ & $10^{-5}$ & 2.8 & 0.61 & 0.58 & 0.21 & 0.79 & - & 10.1 \\
\hline
\end{tabular}

$T D$ thermal deactivation parameter; $\alpha$ a part of excited energy changed promptly into heat; $K_{1}, K_{2}$ deconvolution amplitudes; $\Phi_{\mathrm{T}}$ triplet population; $\tau_{1}, \tau_{2}$ decay times. Based on $[21,23,24]$

The $T D$ values were evaluated for the experiments done at $10 \mathrm{~Hz}$ light modulation frequency at the $\mathrm{Q}$ and Soret bands of $\mathbf{1}, \mathbf{2}$, and $\mathbf{3}$ to $\mathbf{5}$, respectively. $\tau_{1} \leq 0.4 \mu \mathrm{s}$

$\Delta T D= \pm 0.1, \Delta \alpha= \pm 0.06, \Delta K_{1}, \Delta K_{2}= \pm 0.01, \Delta \Phi_{\mathrm{T}}= \pm 0.10, \Delta \tau_{2}=0.01 \mu \mathrm{s}$ to $0.03 \mu \mathrm{s}$

samples. According to [16,17], the decay time shorten by the $N$ factor $(N$-number of monomers which constitute aggregates). For samples $\mathbf{1}$ and $\mathbf{2}$ the numbers could be 2 and 4, respectively. Apart from the changes in the decay times, the small "blue" 
wavelength shifts of the absorption bands are observed implying that the H-types of aggregates can be formed.

The second part of this section deals with samples $\mathbf{3}, \mathbf{4}$, and $\mathbf{5}$ and concerns the triplet behavior of the porphyrin covalently linked to polymers. The photoacoustic spectra confirm heat liberation in the samples dealing with internal conversion and intersystem-crossing processes (Fig. $4 \mathrm{~b}$ presents an example of PAS of sample $5^{\mathrm{I}}$ at $v=10 \mathrm{~Hz}$ ). The $T D$ parameters are compiled in Table 2 . In the low concentrated $\mathbf{3 , 4}$, and $\mathbf{5}$, the $T D$ values range from about 0.4 to 3.3. The differences in TD's could result in the dye's structure and in the polymer molecular weights; however, the differences in TD's are not so drastic. Sample 4 does not fluoresce and most of the energy could be expected to be changed into heat. However, the differences in TD's in sample $\mathbf{4}$ when compared to its counterparts $\mathbf{3}$ or $\mathbf{5}$ are not spectacular as would be expected for the non-fluorescent system. The linear regression correlation factors (between expected theoretical and experimental data) do not reach unity [61]. Thus, we can assume that not only fast processes in monomers are involved in thermal relaxation but also slow deactivation with triplet participation contributes to thermal deactivation to the ground state. Thus, we can expect to have some weakly interacting aggregates in our porphyrin-polymer samples with triplet state enhancement as expected for weakly fluorescent systems. The LIOAS data confirm this expectation. On the basis of the LIOAS experiments, we have evaluated the values of some parameters (reported in Table 2). The values of $\alpha$ and $K_{1}$ evaluated on the basis of the Marti et al. approach [48] are in very good accordance with those estimated on the basis of the Rudzki-Small et al. method [49] and describe how much absorbed energy is dissipated by the systems in prompt processes at a time shorter than $0.4 \mu \mathrm{s}$; these parameters evidently show that about $40 \%$ to $60 \%$ of excitation is deactivated as a result of thermal relaxation in prompt processes. The sum of $K_{i}(i=1,2)$ is less than 1 indicating that other processes in the molecules could also contribute to deactivation [49]. These processes could be phosphorescence and thermal relaxation processes occurring in microseconds. Moreover, we cannot exclude processes such as, for example, charge redistribution upon covalent linkage to the polymer (rather weak on the basis of our absorption and fluorescence examinations), generation of singlet oxygen (almost excluded since our LIOAS experiments were performed in a nitrogen atmosphere), and deformation of the molecular skeleton as well as steric effects leading to conformation and aggregation [46].

Intersystem crossing enhancement (expressed as the phosphorescence to fluorescence yield's ratio [2]) will be discussed rather qualitatively in terms of the fluorescence data ( $\tau_{\mathrm{N}}$-deactivation time of the singlet states) and the triplet relaxation time ( $\tau_{2}$ - thermal relaxation with participation of the long-lived triplet states) since we do not know the phosphorescence yields of the porphyrin-polymer samples under study. Table 2 reports the $\tau_{2}$ values evaluated from Eq. (4); the best results of the deconvolution procedure were obtained for two Gaussian components with $\tau_{1} \leq 0.4 \mu$ s and $\tau_{2}$ ranging from $0.5 \mu$ s to $0.7 \mu$ s for $\mathbf{3}$ and $\mathbf{4}$ and up to $10 \mu \mathrm{s}$ for $\mathbf{5}$. There could be some reasons for the differences in $\tau_{2}$. The first one could be charge transfer in the pyridyl porphyrin-polymer system; constancy of the thermal relaxation times of $\mathbf{3}^{\mathrm{I}}$ and $\mathbf{3}^{\mathrm{II}}$ clearly indicates that thermal relaxation is almost unaffected by the presence of the polymer. In aromatic molecules with the pyridyl units, the intramolecular charge transfer could occur as shown in a classic paper of Levinson et al. [10] for pyridocyanine 
and triplet enhancement can be induced by such interactions [46]. Comparison of the data presented in Tables 1 and 2 for the samples in DMSO with those for aggregated porphyrin species in water $[23,24]$ indicates enhancement of intersystem crossing in these dye-polymer systems. A spin-orbit perturbation in $\mathbf{3}$ and $\mathbf{5}$ and creation of weak aggregates in $\mathbf{3}, \mathbf{4}$, and $\mathbf{5}$ should be also taken into consideration. The differences in the time $\tau_{2}$ of samples $\mathbf{3}$ and $\mathbf{4}$ with regard to $\mathbf{5}$ could be explained by the influence of spin-orbit perturbation enhancement. Thus, in our discussion we take into account sample $5^{\mathrm{IV}}$ to avoid consideration of the spin-orbit effect and to make our discussion more transparent. The changes in the relaxation times could have a consequence in the triplet population changes due to the presence of molecular aggregates. If we assume that the triplet enhancement effect occurring in $5^{\mathrm{IV}}$ could not be assigned to spin-orbit perturbation the changes in $\tau_{\mathrm{N}}$ and $\tau_{2}$ of samples $\mathbf{5}^{\mathrm{I}}, \mathbf{5}^{\mathrm{II}}$, and $\mathbf{5}^{\mathrm{III}}$ in DMSO (Tables 1,2 ) can be considered as due to weakly interacting aggregates. Moreover, from comparison of the data of $\mathbf{3}$ and $\mathbf{4}$ in DMSO to those of the relative sample $\mathbf{5}^{\mathrm{IV}}$ in dioxane (Table 1), we can expect that the changes in $\tau_{\mathrm{N}}$ and $\tau_{2}$ show the effect of triplet enhancement resulting from the existence of the aggregated porphyrin species. In samples $\mathbf{5}^{\mathrm{I}}, \mathbf{5}^{\mathrm{II}}$, and $\mathbf{5}^{\mathrm{III}}$ where spin-orbit interactions do not occur, the enhanced effect is less evident. The $\mathbf{5}^{\mathrm{I}}, \mathbf{5}^{\mathrm{II}}$, and $\mathbf{5}^{\mathrm{III}}$ samples differ from those of their metallic counterparts $3 ; \tau_{\mathrm{N}}$ of the former ones are longer than those in their metallic counterparts. On the other hand, the values of the thermal relaxation times are comparable to those found for the monomeric porphyrin species, but a factor of two longer than those in their metallic counterparts. If we exclude spin-orbit interactions in $\mathbf{5}^{\mathrm{I}}, \mathbf{5}^{\mathrm{II}}$, and $5^{\mathrm{III}}$ and compare the data of these samples to those of $\mathbf{3}$ and $\mathbf{4}$ on the one hand, and to those of $\mathbf{5}^{\mathrm{IV}}$ on the other hand, we can believe that the observed differentiations in the decay times could result in the presence of weakly interacting porphyrin aggregates [23].

\section{Conclusions}

On the basis of the presented results, we can conclude as follows. Even though weak interactions of the organic dyes (phthalocyanines and porphyrins) under study are nearly unnoticeable by absorption and only slightly by fluorescence, it is possible for them to be investigated by complementary photothermal methods. As shown, the LIOAS experiment is a perfect tool for detection of weakly interacting aggregates. Such an approach could be a great advantage in searching for new materials for their applications wherever weakly interacting coupled dyes and/or their hybrids with polymers are required and strong aggregates should be avoided, e.g., in new technologies like OLED, OFET, photovoltaics, as well as photomedicine and other processes important in biological sciences.

Acknowledgments The paper has been supported by the Poznan University of Technology, Poland DS-62-176/2011. The phthalocyanine samples were kindly obtained from Prof. R. Ion (ICECHIM-Bucharest, Romania) and porphyrin-polymer samples from Dr. Yu. S. Avlasevich (Max Planck Institute for Polymer Research, Mainz, Germany) 
Open Access This article is distributed under the terms of the Creative Commons Attribution Noncommercial License which permits any noncommercial use, distribution, and reproduction in any medium, provided the original author(s) and source are credited.

\section{References}

1. A.S. Davydov, Theory of Molecular Excitons (McGraw-Hill, New York, 1962)

2. M. Kasha, H.R. Rawls, M.A. El-Bayoumi, Pure Appl. Chem. 11, 371 (1965)

3. K.M. Booth, S.L. Hill, The Essence of Optoelectronics (Prentice Hall, Englewood Cliffs, NJ, 1998)

4. I. Beletskaya, V.S. Tyurin, A.Y. Tsivadze, R. Guilard, C. Stern, Chem. Rev. 109, 1659 (2009)

5. H. Scheer (ed.), Chlorophylls (CRC Press, Boca Raton, FL, 1991)

6. C.J. Brabec, V. Dyakonov, U. Scherf (eds.), Organic Photovoltaics: Materials, Device Physics, and Manufacturing Technologies (Wiley-VCH Verlag GmbH \& Co., Weinheim, 2008)

7. W. Brütting, Physics of Organic Semiconductors (Wiley-VCH Verlag GMBM \& Co., Weinheim, 2005)

8. C.M. Drain, G. Smeureanu, S. Patel, X. Gong, J. Garno, J. Arijeloye, New J. Chem. 30, 1834 (2006)

9. H. Kautsky, H. Merkel, Naturwissenschaften 27, 195 (1939)

10. L. Levison, W.T. Simpson, W. Curtis, J. Am. Chem. Soc. 79, 4314 (1957)

11. A. Szent-Györgyi, Science 124, 873 (1956)

12. Th. Förster, Naturwissenschaften 33, 166 (1946)

13. A.J. Hoff, J. Amesz, in Chlorophylls, ed. by H. Scheer (CRC Press, Boca Raton, FL, 1991), p. 723

14. W. Fudickar, J. Zimmermann, L. Ruhlmann, J. Schneider, B. Röder, U. Siggel, J-H. Fuhrhop, J. Am. Chem. Soc. 121, 9539 (1999)

15. R. Pottier, A. Lachaine, M. Pierre, J.C. Kennedy, Photochem. Photobiol. 47, 669 (1988)

16. E. Orti, J.L. Bredas, C.J. Clarisse, J. Chem. Phys. 92, 1228 (1990)

17. N.C. Maiti, S. Mazumdar, N. Reriasamy, J. Phys. Chem. 102, 1528 (1998)

18. E.S. Dodsworth, A.B.P. Lever, P. Seymour, C.C. Leznoff, J. Phys. Chem. 89, 5698 (1985)

19. M.J. Stillman, J. Porphyr. Phthalocya. 4, 374 (2000)

20. A.J. Barnes, in Proceedings of the 8th International Conference on Molecular Spectroscopy (WrocławLądek Zdrój, 2005), p. 9

21. A. Boguta, A. Wójcik, R.M. Ion, D. Wróbel, J. Photochem. Photobiol. A: Chem. 163, 201 (2004)

22. J. Feitelson, D. Mauzerall, J. Phys. Chem. 100, 7698 (1996)

23. A. Siejak, D. Wróbel, Yu. S. Avlasevich, J. Phys. IV France 137, 331 (2006)

24. A. Siejak, D. Wróbel, B. Laskowska, Yu.S. Avlasevich, Spectrochim. Acta Part A: Mol. Biomol. Spectr. 74, 148 (2009)

25. C.C. Leznoff, A.B.P. Lever, Phthalocyanines: Properties and Applications (VCH, New York, 1996)

26. K.M. Smith, Porphyrins and Metalloporphyrins (Elsevier, Amsterdam, 1975)

27. D. Dolphin, The Porphyrins (Academic Press, New York, 1979)

28. C.M. Drain, A. Voratto, I. Radivojevic, Chem. Rev. 109, 1630 (2009)

29. B. O’Regan, M. Grätzel, Nature 335, 7377 (1991)

30. D. Wróbel, A. Dudkowiak, Mol. Cryst. Liq. Cryst. 448, 15 (2006)

31. J. Birks (ed.), Organic Molecular Photophysics, vols. 1-2 (Wiley, New York, 1973, 1975)

32. J.A.A. Elemans, R. Hameren, R.J.M. Nolte, A.E. Rowan, Adv. Mater. 18, 1251 (2006)

33. A. Mills, S. Le Hunte, J. Photochem. Photobiol. 108, 1 (1997)

34. H. Imahori, Y. Mori, Y. Matano, J. Photochem. Photobiol. C: Photochem. Rev. 4, 51 (2003)

35. F.T. Hong, Molecular Electronics, Biosensors and Biocomputers (Plenum Press, New York, London, 1989)

36. V. Rosenbach-Belkin, L. Chevn, L. Fiedor, Y. Salomon, A. Scherz, in Photodynamic Tumor Therapy, 2nd and 3rd Generation Photosensitizers, ed. by J.G. Moser (Harwood Academic Publishers, Amsterdam, 1998), p. 117

37. D. Wróbel, A. Boguta, in Molecular Low Dimensional and Nanostructured Materials for Advanced Applications, ed by A. Graja, B. Bułka, F. Kajzar (Kluwer Academic Publishers, Dordrecht, The Netherlands, 2000), p. 71

38. D. Wróbel, C.R. Chemie 6, 417 (2003)

39. D. Wróbel, A. Boguta, R.M. Ion, J. Photochem. Photobiol. A: Chem. 138, 7 (2001)

40. R.M. Ion, F. Scarlat, Rev. Chimie 55, 900 (2004)

41. R.M. Ion, I. Yilmaz, O. Bekaroglu, J. Serb, J. Chem. Soc. 64, 453 (1999) 
42. Yu.S. Avlasevich, O.G. Kulinkovich, V.N. Knyukshto, K.N. Solov’ev, J. Appl. Spectr. 66, 597 (1999)

43. A. Boguta, D. Wróbel, Yu.S. Avlasevich, R. Reis, A. Richter, Mater. Sci. 22, 373 (2004)

44. M.A.M.J. Zandvoort, D. Wróbel, P. Lettinga, G. Van Ginkel, Y.K. Levine, Photochem. Photobiol. A: Chem. 62, 279 (1995)

45. J. Lakowicz, Principles of Fluorescence Spectroscopy (Plenum Press, New York, 1999)

46. D. Frąckowiak, A. Planner, A. Waszkowiak, A. Boguta, R.M. Ion, K. Wiktorowicz, Photochem. Photobiol. A: Chem. 141, 101 (2001)

47. S.E. Braslavsky, G.E. Heibel, Chem. Rev. 92, 1381 (1992)

48. C. Marti, O. Jurgens, O. Cuenca, M. Casals, S. Nonell, J. Photochem. Photobiol. A: Chem. 97, 11 (1996)

49. J. Rudzki-Small, L.J. Libertini, E.W. Small, Biophys. Chem. 42, 29 (1992)

50. D. Wróbel, A. Boguta, J. Photochem. Photobiol. A: Chem. 150, 67 (2002)

51. E. Marais, R. Klein, E. Antunes, T.J. Nyokong, J. Mol. Catal. A: Chem. 261, 36 (2007)

52. I. Rosenthal, Photochem. Photobiol. 53, 859 (1991)

53. D. Wróbel, J. Łukasiewicz, A. Boguta, J. Phys. IV France 109, 111 (2003)

54. Yu.S. Avlasevich, V.N. Knyukshto, O.G. Kulinkovich, K.N. Solovyov, J. Appl. Spectr. 67, 663 (2000)

55. V.N. Knyukshto, Yu. S. Avlasevich, O.G. Kulinkovich, K.N. Solovyov, J. Fluoresc. 99, 371 (1999)

56. D. Wróbel, A. Boguta, A. Wójcik, J. Phys. IV France 117, 101 (2004)

57. E. Bociocchi, F. d'Acunzo, C. Galli, Tetrahedron Lett. 33, 315 (1995)

58. B.E. Smart, J. Fluorine Chem. 109, 3 (2001)

59. X-F. Zhang, H-J. Xu, J. Chem. Soc. Faraday Trans. 89, 3347 (1993)

60. D. Wróbel, J. Łukasiewicz, H. Manikowski, Dyes Pigments 58, 7 (2003)

61. A. Rosencwaig, Photoacoustics and Photoacoustic Spectroscopy (Wiley, New York, 1980)

62. A. Dudkowiak, E. Teślak, J. Habdas, J. Mol. Struct. 792-793, 93 (2006)

63. A. Siejak, D. Wróbel, R.M. Ion, J. Photochem. Photobiol. A: Chem. 181, 180 (2006)

64. A. Siejak, D. Wróbel, P. Siejak, B. Olejarz, R.M. Ion, Dyes Pigments 83, 281 (2009) 